\title{
Effects of erythropoietin on ischemia, follicular survival, and ovarian function in ovarian grafts
}

\author{
Monireh Mahmoodi, Malek Soleimani Mehranjani, Seyed Mohammad Ali Shariatzadeh, \\ Hussein Eimani ${ }^{1}$ and Abdulhussein Shahverdi ${ }^{1}$ \\ Department of Biology, Faculty of Science, Arak University, PO Box 381-5688138, Arak, Iran and \\ ${ }^{1}$ Department of Embryology, Royan Institute for Reproductive Biomedicine, Reproductive Biomedicine \\ Research Center, ACECR, Tehran, Iran \\ Correspondence should be addressed to M Soleimani Mehranjani; Email: M-Soleimani@araku.ac.ir
}

\begin{abstract}
Ovarian tissue transplantation is performed to preserve fertility in patients undergoing chemotherapy and radiotherapy. However, ischemia/reperfusion (IR) injury and free radical production occurring during the revascularization of the transplanted tissue are the major limitations of this procedure. The aim of this study was to investigate the effect of erythropoietin (EPO) as an antioxidant on oxidative stress and ovary survival following transplantation. The Naval Medical Research Institute (NMRI) mice (4-5 weeks old) were divided into three groups (six mice per group): control; autograft + saline, and autograft + EPO (500 IU/kg i.p.). After 28 days, ovary compartments were estimated stereologically. DNA fragmentation and plasma malondialdehyde (MDA), progesterone, and estradiol $\left(E_{2}\right)$ concentrations were also evaluated. The results were analyzed using one-way ANOVA and Tukey's test, and the means were significantly different at $\boldsymbol{P}<\mathbf{0 . 0 5}$. The mean total volume of ovary, cortex, and medulla and the number of follicles increased significantly in the autograft + EPO group $(P<\mathbf{0 . 0 1})$. Apoptosis rate in the autograft + EPO group was lower than that in the autograft + saline group. The concentration of MDA decreased significantly in the autografted EPO-treated group than in the autografted saline-treated group $(P<0.01)$. The concentration of $E_{2}$ increased significantly in the autograft $+E P O$ group than in the autograft + saline group $(P<0.01)$. EPO reduced IR injury, increasing follicle survival and function in grafted ovaries.
\end{abstract}

\section{Free Persian abstract}

A Persian (Farsi) translation of the abstract is freely available online at http://www.reproduction-online.org/content/147/5/733/suppl/DC1 Reproduction (2014) 147 733-741

\section{Introduction}

Recent advances in oncological diagnosis and treatments have significantly increased the long-term survival rates of cancer patients (Demeestere et al. 2009, Dath et al. 2010). Unfortunately, cancer treatments can be very harmful, as they frequently result in the loss of both endocrine and reproductive functions in the ovaries of patients undergoing chemotherapy and radiotherapy, which causes premature ovarian failure and infertility (Yang et al. 2008, Dath et al. 2010, Van Eyck et al. 2010).

Transplantation of ovarian tissues has been performed to preserve and restore fertility in cancer survivors (Soleimani et al. 2011, Wang et al. 2012). Despite these encouraging results, there still remain unresolved limitations to the application of the procedure and its success (Demeestere et al. 2009, Dath et al. 2010).

One of the major obstacles of ovary transplantation appears to be ischemia/reperfusion (IR) injury occurring during the time period required for the revascularization of the transplanted tissue, which consequently leads to cytokine and free radical release, platelet activation, and apoptosis (Demeestere et al. 2009, Hemadi et al. 2009, Karaca et al. 2009, Van Eyck et al. 2010, Commin et al. 2012), causing massive primordial follicle loss and shorter lifespan of the transplanted ovary (Demeestere et al. 2009, Van Eyck et al. 2010, Soleimani et al. 2011). Therefore, the application of any approach to minimize ischemic injury during the initial post-transplantation period and establishment of angiogenesis in the ovarian grafts such as the choice of the transplantation site (Israely et al. 2003, 2006, Soleimani et al. 2008, 2010), the use of antioxidants (Nugent et al. 1998, Sapmaz et al. 2003, Sayyah-Melli et al. 2011), angiogenic factors (Commin et al. 2012), and hormonal factors (Yang et al. 2008, Wang et al. 2012) can play an important role in the success of ovarian tissue transplantation (Suzuki et al. 2008, Yang et al. 2008).

Erythropoietin (EPO) is a hematopoietic cytokine (Karaca et al. 2009, Hamed et al. 2010, Commin et al. 2012) that 
is known for its antioxidant, antiapoptotic, and anti-inflammatory properties through the promotion of cell survival signaling cascades (Karaca et al. 2009), upregulation of the expression of antiapoptotic proteins, modulation of the intracellular calcium metabolism, attenuation of $\mathrm{NO}$ production, and inhibition of glutamate release (Karaca et al. 2009, Commin et al. 2012). EPO also stimulates angiogenesis indirectly in the ischemic tissue by increasing the expression of VEGFA and recruiting endothelial progenitor cells (Hamed et al. 2010).

Experimental studies have revealed that EPO has protective effects against IR injury in organs expressing the EPO receptor (Yasuda et al. 2001, Sayyah-Melli et al. 2011) such as the liver, lung, myocardium, retinal neurons, spinal cord, and kidney (Junk et al. 2002, Karaca et al. 2009). Recently, some studies have reported the antioxidative and protective effects of EPO on the IR injury of ovary (Bakan et al. 2009, Karaca et al. 2009). Commin et al. (2012) investigated the effect of angiogenic EPO in xenografts and reported that EPO treatment significantly improved blood vessel density, stromal cell density, and early follicle morphology, but did not reduce the number of follicles lost following transplantation.

Suzuki et al. (2008) also evaluated the effects of EPO on frozen-thawed canine ovaries xenotransplanted into NOD-SCID mice and found that EPO increased the survival rates of primary and transitional follicles.

The effect of EPO, however, has not been investigated yet in the mouse autograft model; therefore, in the present study, we aimed to evaluate the antioxidative and antiapoptotic effects of recombinant human EPO (rhEPO) on IR injury induced during ovarian transplantation and graft survival rate, follicular development, and ovarian function preservation by examining the changes in ovarian tissue and its compartments, DNA fragmentation, plasma malondialdehyde (MDA), progesterone $\left(\mathrm{P}_{4}\right)$, and estradiol $\left(\mathrm{E}_{2}\right)$ concentrations, and vaginal cytology.

\section{Materials and methods}

\section{Mice}

This study was approved by the Animal Ethics Committee of Royan Institute and carried out in accordance with the principles and procedures of laboratory animal care and use. Female Naval Medical Research Institute (NMRI) mice, Swiss type with the strain code N/A (4-5 weeks old), were purchased from Pasteur Institute (Tehran, Iran), and kept in the animal house of Arak University under standard conditions of a daily cycle of $12 \mathrm{~h}$ light: $12 \mathrm{~h}$ darkness at $21 \pm 2{ }^{\circ} \mathrm{C}$ and given free access to sufficient amounts of food and water. The mice were divided into three groups (six mice per group): control (mice without ovariectomy or grafting); autografted mice that were administered daily i.p. injections of physiological saline; and autografted mice treated with EPO (500 IU/kg i.p.). Bilateral ovariectomy was performed in the autografted groups and ovaries were transplanted into the back muscle. Grafts were examined 28 days after transplantation.

\section{Transplantation procedure and EPO treatment}

The mice were anesthetized with an i.p. injection of ketamine (ketamine $100 \mathrm{mg} / \mathrm{kg}$ and ketamine 10\%, Alfasan, Woerden, Holand) and xylazine (xylazine $10 \mathrm{mg} / \mathrm{kg}$ and xylazine $2 \%$, Alfasan). Bilateral incisions were made in the dorsal body wall on each side of the spinal column, and ovariectomy was performed by excision between the uterine horn and the fallopian tube. A small incision $(0.5 \mathrm{~cm})$ was made along the right and left gluteus superficialis muscle fibers. Briefly, using fine watchmaker's forceps, ovarian tissues were picked and autotransplanted into the muscles. Muscle and skin incisions were closed with absorbable suture (Hurchromic 5/0; Iran) and non-absorbable suture (Supalon 5/0; Iran) under aseptic conditions respectively.

In the autografted EPO-treated group, mice were injected with rhEPO- $\alpha$ (rhEPO; $500 \mathrm{IU} / \mathrm{kg}$ i.p.; Exipoetin, Exir Pharmaceutical Co., Boroojerd, Iran) from 1 day before surgery to 7 days after transplantation. In the autografted saline-treated group, mice were injected with normal saline for 7 days.

\section{Histological and stereological study}

After 28 days, the mice were anesthetized with an i.p. injection of ketamine and xylazine, and then the ovarian tissues of the control and autografted groups were rapidly fixed in Bouin's solution for $24 \mathrm{~h}$. They were then dehydrated in ascending concentrations of ethanol (70-100\%) using an automated tissue processor, embedded in paraffin, and blocked.

The 'isector' method was used to obtain isotropic uniform random sections. For this purpose, spherical modules filled with paraffin were chosen to embrace each ovary. These modules, rotated in a random manner, were serially cut into 5 - and $20-\mu \mathrm{m}$ thick sections, followed by systematic random sampling to select 8-12 sections from each ovary, which were, in turn, stained using the hematoxylin and eosin (Merck) method (Howard \& Reed 1998, Soleimani Mehranjani et al. 2010, Karbalay-Doust \& Noorafshan 2012). After deparaffinization and rehydration, ovarian tissue structure was examined stereologically.

\section{Estimation of the volume of ovary, cortex, and medulla}

To estimate the total volume of ovary, cortex, and medulla, an average of 12 sections were randomly selected from $5-\mu \mathrm{m}$ thick sections. The sections were studied using a microscope (Olympus, BX51) at $4 \times$ magnification. The resulting points from the randomly superimposed probe on the images were counted. Using the Cavalieri method, the total volume of the ovary was then estimated:

$V_{\text {total ovary }}=\sum_{i=1}^{n} P \times a(P) \times t$

where $\sum_{i=1}^{n} P$ is the total number of points superimposed on the image of ovarian sections, $a(P)$ is the corresponding area of each point, and $t$ denotes the distance between the sampled sections and the section thickness. The volume density of each 

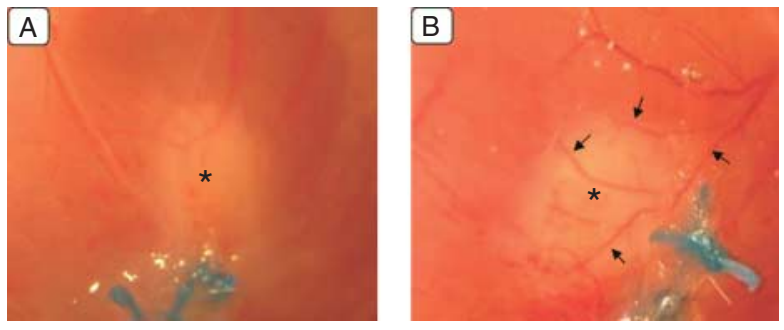

Figure 1 Gross appearance of the graft site 28 days after autotransplantation. (A) Saline-treated group with a low supply of blood vessels. (B) EPO-treated group; neo-vascularization (arrows) surrounding the transplantation site supplies sufficient blood to the graft $(*)$.

ovary compartment was calculated as follows to obtain the volume of the ovary compartments:

$V_{V \text { cortex }}=\frac{\sum_{i=1}^{n} p_{\text {cortex }}}{\sum_{i=1}^{n} p_{\text {total }}}$

where $\sum_{i=1}^{n} P_{\text {total }}$ is the total number of counted points and $\sum_{i=1}^{n} P_{\text {cortex }}$ is the total number of superimposed points on the cortex. In turn, volume density $(V v)$ was multiplied by the total volume of the ovary to estimate the volume of cortex and medulla (Howard \& Reed 1998, Soleimani Mehranjani et al. 2010, Karbalay-Doust \& Noorafshan 2012).

\section{Estimation of the number of follicles}

To estimate the number of follicles, a combination of an unbiased sampling frame and the optical disector design was employed to sample the tissue. Following systematic random sampling, an average of 12 sections were selected from $20-\mu \mathrm{m}$-thick sections, which were then studied using an Olympus microscope with a $100 \times$ oil immersion objective and a high numerical aperture (NA: 1.4). The microscope stage was moved at an equal distance to select microscopic fields. To measure the movement of the stage in the z-axis, a microcator (ND 221 B, Heidenhain, Traunreut, Germany) connected to a computer and a microscope was used. In each microscopic field, $5 \mu \mathrm{m}$ from the top and bottom of the sections were ignored as a guard area against the cutting artifacts (Myers et al. 2004, Soleimani Mehranjani et al. 2010, Karbalay-Doust \& Noorafshan 2012). An unbiased counting frame superimposed on the monitor was used to sample the nucleolus profiles of the oocytes. Identification of different types of follicles was carried out based on the Myers et al. (2004) classification. The selected nucleoli of the oocytes were those that were placed inside or partially placed inside the sampling frame having no contact with the exclusion lines of the frame. About 100-120 oocytes/ovary were analyzed, and the numerical density $(N v)$, defined as the number of the cells in unit volume of the ovary, was estimated as follows:

$N_{V}=\frac{\sum_{i=1}^{n} Q}{h \times \sum_{n=1}^{n} P \times a / f}$

where $\sum Q$ is the total number of counted follicles in the disector height $(h)$ and $a / f$ is the area of each frame and $\sum P$ denotes the total number of frames counted in all the microscopic fields. By multiplying $N_{v}$ by the total volume of the ovary, the total number of follicles was estimated $\left(N_{\text {total }}=N_{V} \times V_{\text {total }}\right.$; Howard \& Reed 1998, Soleimani Mehranjani et al. 2010, Karbalay-Doust \& Noorafshan 2012).

To estimate the mean percentage of ovaries containing corpus luteum in both the autografted saline-treated and EPOtreated groups, sections obtained from each graft were examined, and any ovary that was observed to contain the corpus luteum in its relevant sections was counted as one. Based on the number of ovaries containing the corpus luteum among the other ovaries in each group, the mean percentage of grafts containing the corpus luteum was estimated.

\section{Assessment of apoptosis rate using TUNEL assay}

DNA fragmentation was assessed using TUNEL assay, according to the kit manufacturer's instructions (In Situ Cell Death Detection Kit, Roche). After deparaffinization and rehydration, the 5 - $\mu$ m-thick sections were incubated in $3 \%$ hydrogen peroxide $\left(\mathrm{H}_{2} \mathrm{O}_{2}\right.$; Merck) for $10 \mathrm{~min}$ to neutralize endogenous
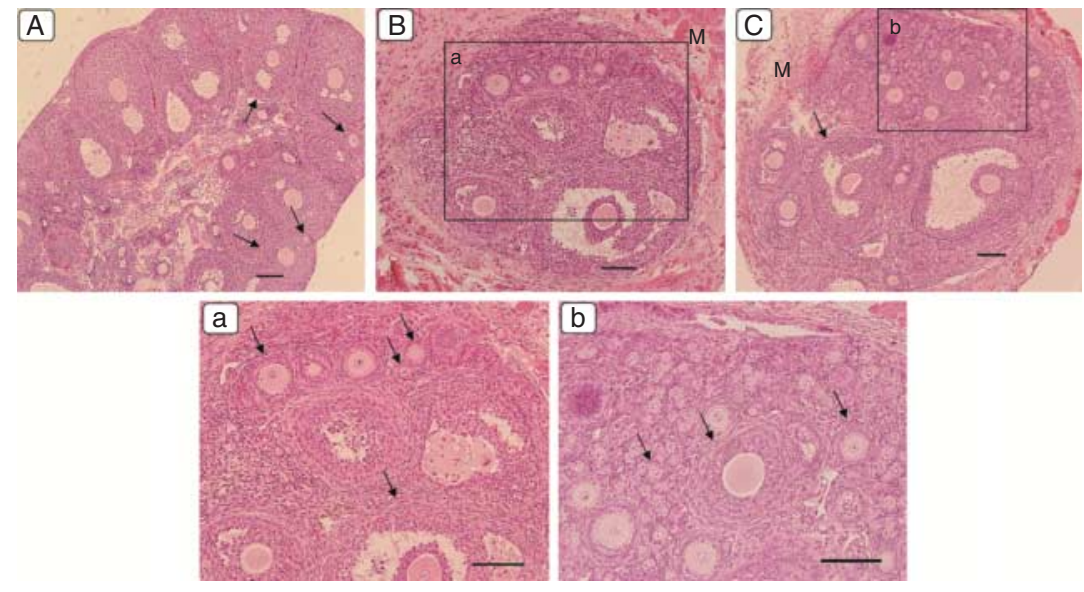

Figure 2 Micrographs of the ovary tissue $(5-\mu \mathrm{m}$-thick sections with hematoxylin and eosin (H\&E) staining) in different groups of mice 28 days after autotransplantation. The arrows show the follicles at the different stages of development. (A) Control group, showing a significant number of follicles in different stages of development. (B, a) Autografted saline-treated group, showing a reduction in ovary size and the number of follicles, especially primordial follicles. Follicles were observed in different stages of development. (C, b) Autografted EPO-treated group, showing a significant number of primordial, growing, and antral follicles (scale bar: $100 \mu \mathrm{m} ; \mathrm{M}$, muscle). 

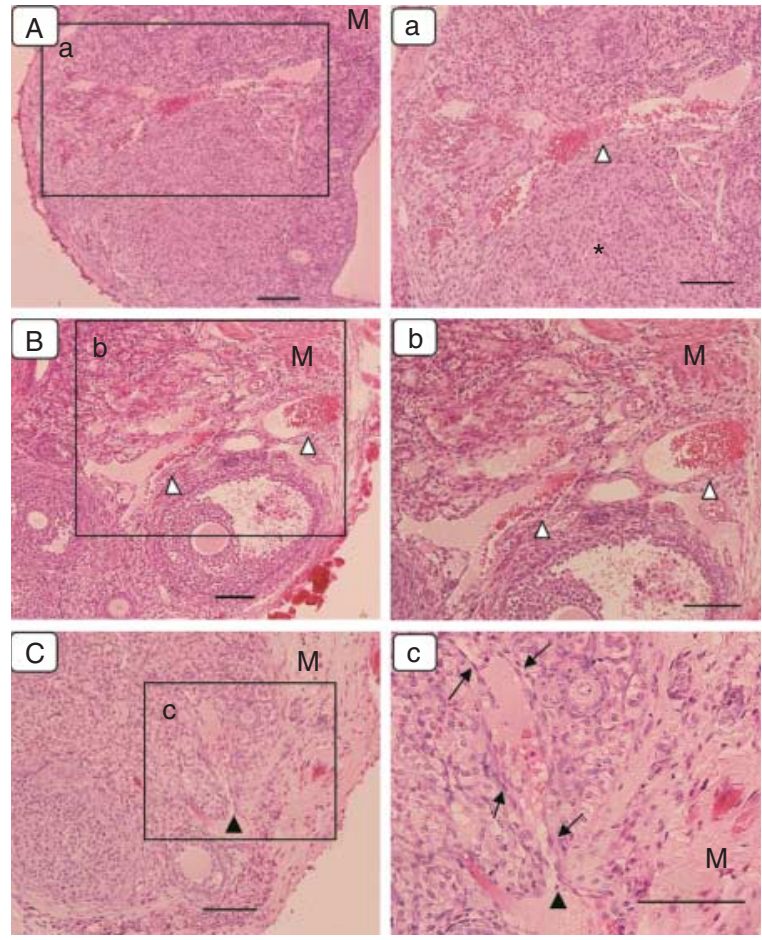

Figure 3 Histological sections of ovarian grafts treated with EPO 28 days after autotransplantation. (A, a) and (B, b) Functional blood vessels containing erythrocytes (open triangle) and corpus luteum ${ }^{*}$ ) can be detected within the transplanted tissue. (C, c) Vessels with anastomosis (filled triangle) in the ovarian tissue and muscle fibers of the autografted EPO-treated group. The arrows show the endothelial cells (scale bar: $100 \mu \mathrm{m} ; \mathrm{M}$, muscle).

peroxidases, followed by digestion with $20 \mu \mathrm{g} / \mathrm{ml}$ proteinase $\mathrm{K}$ for $30 \mathrm{~min}$ at $37^{\circ} \mathrm{C}$. The TUNEL reaction mixture was added, and the slides were incubated for $60 \mathrm{~min}$ at $37^{\circ} \mathrm{C}$ in a humidified dark chamber, followed by incubation with Converter-POD at $37^{\circ} \mathrm{C}$ for $30 \mathrm{~min}$. A series of tissue sections were incubated in the reaction buffer without $\mathrm{TdT}$ as a negative control. The samples were stained with diaminobenzidine substrate (Roche) for $10 \mathrm{~min}$, followed by counterstaining with hematoxylin and washed with distilled water, dehydrated, mounted with Entellan (Merck), and examined using a light microscope. Oocytes and follicular cells containing stained nuclei (dark brown) were considered to be TUNEL positive. If more than $10 \%$ of the follicular cells were TUNEL positive, the follicle was considered to be apoptotic (Yang et al. 2008).

\section{Hormone assay}

After 28 days, blood samples were collected, and after centrifugation $(3000 \mathrm{~g}$ for $5 \mathrm{~min}$ ), serum was analyzed in duplicates using the $\mathrm{P}_{4}$ Kit (DRG Progesterone ELISA Kit, and EIA-1561; DRG Instruments GmbH, Marburg, Germany) with a sensitivity of $0.045 \mathrm{ng} / \mathrm{ml}$ and an assay range of $0-40 \mathrm{ng} / \mathrm{ml}$ and the $\mathrm{E}_{2}$ Kit (DRG Estradiol ELISA Kit, ElA-2693; DRG Instruments $\mathrm{GmbH}$ ) with a sensitivity of $9.714 \mathrm{pg} / \mathrm{ml}$ and assay range of 9.7-2000 pg/ml, according to the manufacturer's instructions.

\section{Measurement of MDA concentration}

The concentration of MDA, indicating lipid peroxidation, was measured using the thiobarbituric acid (TBA) method. The concentration was measured according to the kit manufacturer's instructions (NWLSS NWK-MDA01, Vancouver, Canada) using samples of blood serum collected on days 7 and 28 after transplantation. Later, $10 \mu \mathrm{l}$ of butylated hydroxytoluene, $250 \mu \mathrm{l}$ of serum and/or calibrators, $250 \mu \mathrm{l}$ of acid reagent, and 2-TBA were added to the samples and vortexed vigorously, followed by incubation at $60{ }^{\circ} \mathrm{C}$ for $60 \mathrm{~min}$. The absorbance was recorded at $532 \mathrm{~nm}$ with a spectrophotometer (T80 +, PG Instruments Ltd, London, UK), and MDA concentration was calculated based on the absorption standard curve.

\section{Assessment of vaginal cytology}

Seven days after surgery until the appearance of the first typical estrous profile (cornified epithelial cells) and then weekly until the time the mice were killed, vaginal cytology, representing the resumption of cyclic ovarian activity, was assessed. Vaginal smear of each mouse was observed immediately under a light microscope $(100 \times)$ to be classified as proestrous, estrous, metestrous, or diestrous (Byers et al. 2012).

\section{Statistical analysis}

The results were analyzed by one-way ANOVA and Tukey's test, using the SPSS V16/0 Software, and the means were considered to be significantly different at $P<0.05$.

\section{Results}

\section{Ovarian histological aspects}

Ovaries recovered successfully in both the autografted groups $(100 \%$ recovery rate); however, the ovary size decreased, which was more significant in the autografted saline-treated group. The graft sites appeared to be more vascularized in the autografted EPO-treated group than in the autografted saline-treated group (Fig. 1).

The follicles of the recovered ovaries at different stages of development were detectable through histological examination, mainly at the immature stage in the autografted EPO-treated group (Fig. 2). Moreover, corpora lutea were observed in the grafted ovaries of some mice, and the ovaries of the autografted

Table 1 Comparison of the mean total volume of ovary, cortex, and medulla in different groups of mice 28 days after autotransplantation of ovarian tissue following 7 days of EPO treatment (500 IU/kg).

\begin{tabular}{lccr}
\hline Groups & $\begin{array}{c}\text { Volume of } \\
\text { ovary }\left(\mathrm{mm}^{3}\right)\end{array}$ & $\begin{array}{c}\text { Volume of } \\
\text { cortex }\left(\mathrm{mm}^{3}\right)\end{array}$ & $\begin{array}{c}\text { Volume of } \\
\text { medulla }\left(\mathrm{mm}^{3}\right)\end{array}$ \\
\hline Control & $1.92 \pm 0.08^{\mathrm{a}}$ & $1.74 \pm 0.08^{\mathrm{a}}$ & $0.19 \pm 0.01^{\mathrm{a}}$ \\
Autograft+saline & $1.09 \pm 0.12^{\mathrm{b}}$ & $1.06 \pm 0.11^{\mathrm{b}}$ & $0.025 \pm 0.01^{\mathrm{b}}$ \\
Autograft+EPO & $1.45 \pm 0.26^{\mathrm{c}}$ & $1.40 \pm 0.26^{\mathrm{c}}$ & $0.05 \pm 0.01^{\mathrm{c}}$ \\
\hline
\end{tabular}

Values are means \pm s.D. The means with different codes letter are significantly different (one-way ANOVA and Tukey's test, $P<0.05$ ). 
Table 2 Comparison of the mean number of primordial, primary, preantral, and antral follicles and the mean total number of follicles in different groups of mice 28 days after autotransplantation of ovarian tissue following 7 days of EPO treatment (500 IU/kg).

\begin{tabular}{lccccc}
\hline Groups & Primordial follicles & Primary follicles & Preantral follicles & Antral follicles & Total \\
\hline Control & $1879.50 \pm 89.70^{\mathrm{a}}$ & $572.5 \pm 33.04^{\mathrm{a}}$ & $307.00 \pm 25.35^{\mathrm{a}}$ & $117.83 \pm 8.06^{\mathrm{a}}$ & $2876.83 \pm 103.93^{\mathrm{a}}$ \\
Autograft + saline & $977.67 \pm 131.87^{\mathrm{b}}$ & $302.00 \pm 25.42^{\mathrm{b}}$ & $173.33 \pm 14.42^{\mathrm{b}}$ & $53.17 \pm 10.44^{\mathrm{b}}$ & $1506.17 \pm 132.25^{\mathrm{b}}$ \\
Autograft +EPO & $1542.00 \pm 114.37^{\mathrm{c}}$ & $491.50 \pm 28.67^{\mathrm{c}}$ & $210.67 \pm 21.11^{\mathrm{c}}$ & $82.17 \pm 7.19^{\mathrm{c}}$ & $2326.33 \pm 112.68^{\mathrm{c}}$ \\
\hline
\end{tabular}

Values are means \pm s.D. The means with different code letters are significantly different (one-way ANOVA and Tukey's test, $P<0.05$ ).

saline-treated group had fewer corpora lutea. No significant difference was observed in the morphological features of the follicles and the tissue integrity between the control and the autografted groups, and no sign of fibrosis was detected in the autografted groups (Fig. 2). Establishment of well-organized blood vessels between the grafts and the host and also the existence of functional blood vessels in the autografted groups were apparent (Fig. 3).

\section{Volume of ovary, cortex, and medulla}

The mean total volume of ovary, cortex, and medulla in both the autografted groups decreased significantly compared with that in the control group $(P<0.001)$, while a significant increase was observed in the autografted EPO-treated group than in the autografted saline-treated group $(P<0.01)$ (Table 1$)$.

\section{Number of follicles}

The mean number of primordial, primary, preantral, and antral follicles, as well as the mean total number of follicles, decreased significantly in the autografted groups than in the control group $(P<0.001)$. Moreover, the values of the above-mentioned parameters increased significantly in the autografted EPO-treated group than in the autografted saline-treated group $(P<0.001$; Table 2$)$. Corpus lutea were detected in $33.33 \%$ of the grafts in the non-treated group and $66.67 \%$ of the grafts in the autografted EPO-treated group.

\section{Apoptosis rate}

The evaluation of the rate of apoptosis indicated that the percentage of apoptotic follicles was significantly higher in the autografted saline-treated group $(11.29 \pm 2.78)$ than in the autografted EPO-treated group $(2.17 \pm 0.61)$ and the control group $(1.65 \pm 0.64)(P<0.001)$. On the other hand, the rate of apoptosis in the ovarian follicles of the autografted EPO-treated group was relatively similar to that in the ovarian follicles of the control group $(P>0.05$; Figs 4 and 5).

\section{Hormone concentrations}

The concentrations of $\mathrm{P}_{4}$ and $\mathrm{E}_{2}$ in both the autografted saline-treated and EPO-treated groups exhibited a
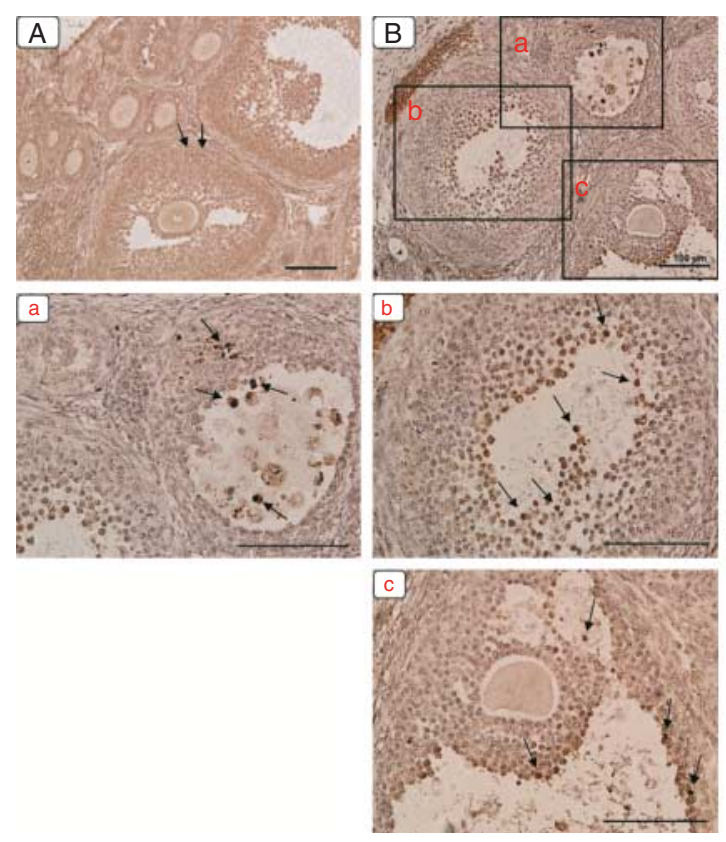

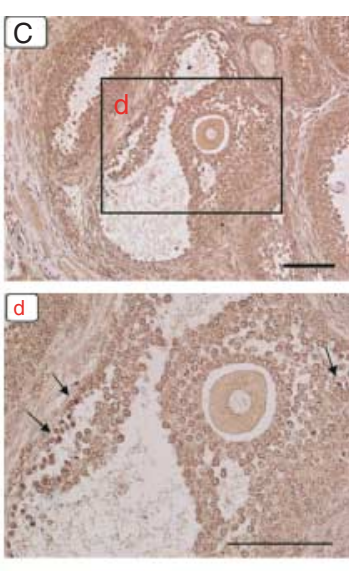

Figure 4 Assessment of apoptosis rate by TUNEL staining in ovarian grafts 28 days after autotransplantation. (A) Control group. (Ba, b and c) Autografted saline-treated group; TUNEL-positive follicular cells (dark brown nucleus) are marked. The arrows show the apoptotic cells. (C, d) Autografted EPO-treated group; a considerable number of apoptotic cells in stroma and follicles were not observed (scale bar: $100 \mu \mathrm{m}$ ). 


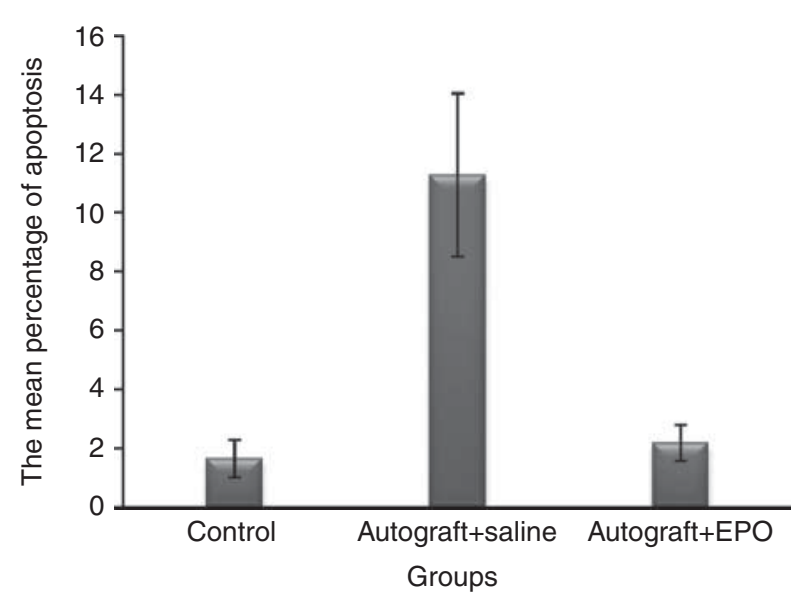

Figure 5 Comparison of apoptosis rate in different groups of mice 28 days after autotransplantation of ovarian tissue following 7 days of EPO treatment $(500 \mathrm{lU} / \mathrm{kg})$.

considerable reduction compared with those in the control group $(P<0.001)$. The concentration of $\mathrm{P}_{4}$ did not differ in both the autografted groups $(P>0.05)$, while that of $E_{2}$ increased significantly in the autografted EPO-treated group than in the autografted saline-treated group $(P<0.01)$ (Table 3$)$.

\section{Concentration of MDA}

The concentration of MDA measured on days 7 and 28 following transplantation increased significantly in the autografted saline-treated group than in the control group $(P<0.001)$. A significant reduction in the concentration of MDA was observed in the autografted EPO-treated group when compared with that in the autografted saline-treated group at 7 days $(P<0.001)$ and the control group $(P<0.01)$, while no significant difference in the concentration was observed between the autografted EPO-treated group and the control group $(P>0.05)$ (Table 4).

\section{Vaginal cytology}

The recovery rate of estrous cycle was $100 \%$ in both the autografted groups. Autografted mice had cornified epithelial cells 9-12 days after transplantation. However, the initiation of estrous cycle was more rapid in the autografted EPO-treated group than in the autografted saline-treated group $(P<0.001 ;$ Table 5).

\section{Discussion}

In this study, EPO was administered 1 day before until 7 days after transplantation, as previous investigations have shown that the establishment of well-organized blood vessels between the graft and the host occurs on day 7 after transplantation (Israely et al. 2004,
Damous et al. 2009). On the other hand, EPO treatment for 3 days after transplantation has been shown to have no considerable effects on the massive loss of follicles after transplantation (Commin et al. 2012).

We also chose the back muscle site, as more rapid revascularization occurs in an i.m. transplantation site than in other graft sites (Israely et al. 2003, Soleimani et al. 2008, 2010, Dath et al. 2010, Li et al. 2010, Commin et al. 2012).

As ovariectomy leads to an elevation in the concentrations of gonadotropins, which helps follicle development in the grafts (Commin et al. 2012), the animals were ovariectomized and both ovaries were transplanted. Furthermore, it is essential to remove the recipient's ovaries to prevent any host secretion of ovarian hormones, which can interfere with the vaginal cytology assessment (Commin et al. 2012).

In the present study, no pathological changes or any sign of fibrosis was observed in the autografted EPO-treated mice, which is in agreement with the results reported by other investigators, who investigated the protective effect of EPO against the oxidative damage associated with reperfusion following ovarian torsion in rats (Karaca et al. 2009, Sayyah-Melli et al. 2011).

EPO may affect the survival of transplanted organ tissues by reducing IR injury and preventing apoptosis (Suzuki et al. 2008). The beneficial effects of EPO could also be attributed to its antioxidant effects, which reduce lipid peroxidation and oxidative injury (Karaca et al. 2009, Sayyah-Melli et al. 2011).

Our results also demonstrated that the mean total volume of ovary, cortex, and medulla decreased significantly in the autografted groups, which could be due to the granulosa and oocyte cells undergoing apoptosis especially in growing follicles, leading to the degradation and atresia of follicles (Hemadi et al. 2009). Other investigations have also reported a reduction in the ovary size following transplantation (Kim et al. 2002, Hemadi et al. 2009); moreover, treatment of the grafts with EPO has been shown to significantly increase the volume of ovary, cortex, and medulla. This could be due to the antioxidant properties of EPO, which reduce the inflammatory responses; EPO also increases the expression of angiogenic factors and microvascular density along with the expression of cell survival factors such as protein kinase $B$, reducing the rate of apoptosis

Table 3 Comparison of the mean concentrations of progesterone and estradiol in different groups of mice 28 days after autotransplantation of ovarian tissue following 7 days of EPO treatment (500 IU/kg).

\begin{tabular}{lcc}
\hline Groups & Progesterone $(\mathrm{ng} / \mathrm{ml})$ & Estradiol $(\mathrm{pg} / \mathrm{ml})$ \\
\hline Control & $2.81 \pm 0.94^{\mathrm{a}}$ & $43.25 \pm 5.68^{\mathrm{a}}$ \\
Autograft + saline & $0.80 \pm 0.13^{\mathrm{b}}$ & $26.21 \pm 4.311^{\mathrm{b}}$ \\
Autograft + EPO & $1.43 \pm 0.36^{\mathrm{b}}$ & $35.98 \pm 3.81^{\mathrm{c}}$ \\
\hline
\end{tabular}

Values are means \pm s.D. The means with different code letters are significantly different (one-way ANOVA and Tukey's test, $P<0.05$ ). 
Table 4 Comparison of the concentration of malondialdehyde (MDA, $\mu \mathrm{M}$ ) in different groups of mice 7 and 28 days after autotransplantation of ovarian tissue following 7 days of EPO treatment (500 IU/kg).

\begin{tabular}{lcc}
\hline & \multicolumn{2}{c}{ MDA } \\
\cline { 2 - 3 } Groups & $\begin{array}{c}7 \text { days after } \\
\text { transplantation }\end{array}$ & $\begin{array}{c}\text { 28 days after } \\
\text { transplantation }\end{array}$ \\
\hline Control & $3.74 \pm 0.61^{\mathrm{a}}$ & $3.45 \pm 0.69^{\mathrm{a}}$ \\
Autograft+saline & $7.50 \pm 0.89^{\mathrm{b}}$ & $4.94 \pm 0.32^{\mathrm{b}}$ \\
Autograft +EPO & $4.70 \pm 0.76^{\mathrm{a}}$ & $3.88 \pm 0.58^{\mathrm{a}}$ \\
\hline
\end{tabular}

Values are means \pm s.D. The means with different code letters are significantly different (one-way ANOVA and Tukey's test, $P<0.05$ ).

and attenuating the IR injury (Karaca et al. 2009, Hamed et al. 2010, Sayyah-Melli et al. 2011, Commin et al. 2012). Therefore, it could be deduced that EPO prevents the apoptosis of ovarian cells during the first few days of transplantation until the establishment of revascularization, protecting against tissue initial degeneration, which prevents ovary shrinkage.

The given dose and duration of EPO administration did not compensate for the reduction in the values of the above-mentioned parameters to the control level; therefore, further studies with other doses of EPO, or even modified periods of treatment, may improve the obtained results.

Our results demonstrated a reduction in the number of follicles in both the autografted groups, indicating an increase in the number of apoptotic follicles, which could be due to the depletion of follicular reserve during IR processes induced by free radicals and lipid peroxidation (Demeestere et al. 2009, Soleimani et al. 2011, Commin et al. 2012, Wang et al. 2012). Primordial follicles can tolerate episodes of ischemic conditions for $3 \mathrm{~h}$ at $4{ }^{\circ} \mathrm{C}$ (Eimani et al. 2011), whereas the growing follicles are mostly lost during the first few days of ischemic conditions (Hemadi et al. 2009, Commin et al. 2012, Wang et al. 2012). Any growing follicles present in the graft within days of transplantation are probably derived from primordial follicles present at the time of transplantation (Eimani et al. 2011). In the present study, administration of EPO tended to significantly increase the proportion of different types of follicles, both primordial and growing, entering the next stage of development. Ovarian stromal cells surrounding the follicles, which play an important role in tissue integrity, normal ovarian function, and follicle growth and survival (Soleimani et al. 2011, Commin et al. 2012), are too sensitive to ischemic conditions (Demeestere et al. 2009). Our histological findings demonstrated ovarian stromal tissue to be normal in the autografted EPO-treated group. In this way, EPO would shorten the time needed for the estrous cycle to recover following ovary transplantation, and hence restoration of the estrous cycle was more rapid in the autografted EPOtreated group than in the autografted saline-treated group.

The effect of EPO on folliculogenesis with better preservation of primordial and primary follicles and also stromal integrity may be related to the antioxidant, antiapoptotic, and cell protective functions of EPO along with its hematopoietic effect (Karaca et al. 2009, Commin et al. 2012). However, the efficacy of our treatment method ( 1 day before until 7 days after transplantation with i.p. injections) should also be considered, as in another study in which EPO was administrated subcutaneously at a similar dose for 3 days, massive follicular loss still occurred (Commin et al. 2012).

Endocrinology of ovary-grafted animals helps us to understand follicular and oocyte development and also the return of ovarian function (Callejo et al. 2002, Li et al. 2010). $E_{2}$ and $P_{4}$ are the most representative steroids (Li et al. 2010). In this study, the mean serum concentration of $E_{2}$ increased significantly in the autografted EPO-treated group. This is mainly due to a significant increase in the number of antral follicles in the grafts, which are responsible for the production of steroid hormones, most importantly $\mathrm{E}_{2}$ (Greenfeld et al. 2007), indicating that the follicles preserve their endocrine function following transplantation.

EPO reduced the plasma concentration of MDA significantly to the control level, which could be a major factor in the reduction of grafted ovarian necrosis in the autografted EPO-treated group (Sapmaz et al. 2003). The beneficial effects of EPO regarding the decrease in the concentrations of MDA have also been reported by other investigators (Bakan et al. 2009, Sayyah-Melli et al. 2011).

As has been mentioned already, EPO through the prevention of oxidative stress during transplantation will lead to a reduction of IR injury (Soleimani et al. 2011). The protective effects of EPO are via the inhibition of lipid peroxidation and restoration of cytosolic catalase, heme oxygenase 1, and glutathione peroxidase activities in erythrocytes (Karaca et al. 2009, Sayyah-Melli et al. 2011). In addition, it has been suggested that EPO can increase the number of erythrocytes, leading to a reduction in cellular oxidative stress (Sayyah-Melli et al. 2011). EPO also decreases the extent of DNA fragmentation and caspase 3 activity (Hamed et al. 2010) and enhances ovarian angiogenesis, which can reduce tissue hypoxia and apoptosis (Soleimani etal. 2011, Commin etal. 2012).

In short, the present study indicated that treatment of grafts with EPO could reduce IR injury and oxidative stress and improve graft survival rate and follicular development. EPO also restores ovarian function through the restoration of the estrous cycle and hormonal function.

Table 5 Comparison of the mean recovery of estrous cycle in different groups of mice.

\begin{tabular}{lc}
\hline Groups & Starting day of estrous cycle \\
\hline Control & $8.17 \pm 0.75^{\mathrm{a}}$ \\
Autograft + saline & $11.50 \pm 0.55^{\mathrm{b}}$ \\
Autograft + EPO & $9.50 \pm 0.55^{\mathrm{c}}$ \\
\hline
\end{tabular}

Values are means \pm s.D. The means with different code letters are significantly different (one-way ANOVA and Tukey's test, $P<0.05$ ). 


\section{Declaration of interest}

The authors declare that there is no conflict of interest that could be perceived as prejudicing the impartiality of the research reported.

\section{Funding}

This study was supported by the Arak University.

\section{Acknowledgements}

The authors are grateful to Dr Masoud Hemadi, Mr Mehdi Farahani, Dr Rouhollah Fathi, and Mrs Maryam Saber for their technical assistance during this study and also to the Arak University for providing financial support.

\section{References}

Bakan V, Ciralik H, Tolun FI, Atli Y, Mil A \& Ozturk S 2009 Protective effect of erythropoietin on torsion/detorsion injury in rat model. Journal of Pediatric Surgery 44 1988-1994. (doi:10.1016/j.jpedsurg.2009.02.071)

Byers SL, Wiles MV, Dunn SL \& Taft RA 2012 Mouse estrous cycle identification tool and images. PLOS ONE 7 e35538. (doi:10.1371/ journal.pone.0035538)

Callejo J, Vilaseca S, Ordi J, Cabre S, Lailla JM \& Balasch J 2002 Heterotopic ovarian transplantation without vascular pedicle in syngeneic Lewis rats: long-term evaluation of effects on ovarian structure and function. Fertility and Sterility 77 396-402. (doi:10.1016/S00150282(01)02970-3)

Commin L, Buff S, Rosset E, Galet C, Allard A, Bruyere P, Joly T, Guerin P \& Neto V 2012 Follicle development in cryopreserved bitch ovarian tissue grafted to immunodeficient mouse. Reproduction, Fertility, and Development 24 461-471. (doi:10.1071/RD11166)

Damous LL, Silva SM, Carbonel AP, Simoes RS, Simoes MJ \& Montero EF 2009 Effect of remote ischemic preconditioning on rat estradiol serum levels and follicular development after ovarian transplantation. Transplantation Proceedings 41 830-833. (doi:10.1016/j.transproceed.2009. 01.070)

Dath C, Van Eyck AS, Dolmans MM, Romeu L, Delle Vigne L, Donnez J \& Van Langendonckt A 2010 Xenotransplantation of human ovarian tissue to nude mice: comparison between four grafting sites. Human Reproduction 25 1734-1743. (doi:10.1093/humrep/deq131)

Demeestere I, Simon P, Emiliani S, Delbaere A \& Englert Y 2009 Orthotopic and heterotopic ovarian tissue transplantation. Human Reproduction Update 15 649-665. (doi:10.1093/humupd/dmp021)

Eimani H, Behbahanian A, Zeinali B, Rezazade Valoujerdi M, Eftekhari P, Shahverdi AH, Gourabi H \& Golkar-Narenji A 2011 Heterotopic autotransplantation of vitrified mouse ovary. Reproductive Medicine and Biology 10 267-275. (doi:10.1007/s12522-011-0100-y)

Greenfeld CR, Babus JK, Furth PA, Marion S, Hoyer PB \& Flaws JA 2007 $\mathrm{BAX}$ is involved in regulating follicular growth, but is dispensable for follicle atresia in adult mouse ovaries. Reproduction 133 107-116. (doi:10.1530/REP-06-0144)

Hamed S, Egozi D, Kruchevsky D, Teot L, Gilhar A \& Ullmann Y 2010 Erythropoietin improves the survival of fat tissue after its transplantation in nude mice. PLOS ONE 5 e13986. (doi:10.1371/journal.pone. 0013986)

Hemadi M, Abolhassani F, Akbari M, Sobhani A, Pasbakhsh P, AhrlundRichter L, Modaresi MH \& Salehnia M 2009 Melatonin promotes the cumulus-oocyte complexes quality of vitrified-thawed murine ovaries; with increased mean number of follicles survival and ovary size following heterotopic transplantation. European Journal of Pharmacology 618 84-90. (doi:10.1016/j.ejphar.2009.07.018)

Howard CV \& Reed MG 1998 In Unbiased Stereology: Three-Dimensional Measurement in Microscopy. Microscopy handbook series 41. Oxford, UK: Bios Scientific Publishers.
Israely T, Dafni H, Granot D, Nevo N, Tsafriri A \& Neeman M 2003 Vascular remodeling and angiogenesis in ectopic ovarian transplants: a crucial role of pericytes and vascular smooth muscle cells in maintenance of ovarian grafts. Biology of Reproduction 68 2055-2064. (doi:10.1095/biolreprod.102.011734)

Israely T, Dafni H, Nevo N, Tsafriri A \& Neeman M 2004 Angiogenesis in ectopic ovarian xenotransplantation: multiparameter characterization of the neovasculature by dynamic contrast-enhanced MRI. Magnetic Resonance in Medicine 52 741-750. (doi:10.1002/mrm.20203)

Israely T, Nevo N, Harmelin A, Neeman M \& Tsafriri A 2006 Reducing ischaemic damage in rodent ovarian xenografts transplanted into granulation tissue. Human Reproduction 21 1368-1379. (doi:10.1093/ humrep/del010)

Junk AK, Mammis A, Savitz SI, Singh M, Roth S, Malhotra S, Rosenbaum PS, Cerami A, Brines M \& Rosenbaum DM 2002 Erythropoietin administration protects retinal neurons from acute ischemia-reperfusion injury. PNAS 99 10659-10664. (doi:10.1073/ pnas.152321399)

Karaca M, Odabasoglu F, Kumtepe Y, Albayrak A, Cadirci E \& Keles ON 2009 Protective effects of erythropoietin on ischemia/reperfusion injury of rat ovary. European Journal of Obstetrics, Gynecology, and Reproductive Biology 144 157-162. (doi:10.1016/j.ejogrb.2009.03.011)

Karbalay-Doust S \& Noorafshan A 2012 Stereological estimation of ovarian oocyte volume, surface area and number: application on mice treated with nandrolone decanoate. Folia Histochemica et Cytobiologica 50 275-279. (doi:10.5603/FHC.2012.0037)

Kim SS, Soules MR \& Battaglia DE 2002 Follicular development, ovulation, and corpus luteum formation in cryopreserved human ovarian tissue after xenotransplantation. Fertility and Sterility 78 77-82. (doi:10.1016/ S0015-0282(02)03144-8)

Li F, Tao Y, Zhang Y, Li Y, Fang F, Liu Y, Cao H, Zhang X \& Zhou S 2010 Follicle growth and oocyte development after ovary transplantation into back muscle of immune-intact adult castrated male mice. Reproduction 140 465-476. (doi:10.1530/REP-10-0076)

Myers M, Britt KL, Wreford NG, Ebling FJ \& Kerr JB 2004 Methods for quantifying follicular numbers within the mouse ovary. Reproduction 127 569-580. (doi:10.1530/rep.1.00095)

Nugent D, Newton H, Gallivan L \& Gosden RG 1998 Protective effect of vitamin E on ischaemia-reperfusion injury in ovarian grafts. Journal of Reproduction and Fertility 114 341-346. (doi:10.1530/jrf.0.1140341)

Sapmaz E, Ayar A, Celik H, Sapmaz T, Kilic N \& Yasar MA 2003 Effects of melatonin and oxytetracycline in autologous intraperitoneal ovary transplantation in rats. Neuro Endocrinology Letters 24 350-354.

Sayyah-Melli M, Kazemi-Shishvan M, Solaimani-Rad J, Rashidi MR, Roshangar L, Rashtchizadeh N, Ouladesahebmadarek E, Ghojazadeh M \& Mashrabi O 2011 The ovario-protective effect of erythropoietin against oxidative damage associated with reperfusion following ovarian torsion in rat. American Journal of Animal and Veterinary Sciences 6 18-24. (doi:10.3844/ajavsp.2011.18.24)

Soleimani R, Van der Elst J, Heytens E, Van den Broecke R, Gerris J, Dhont M, Cuvelier C \& De Sutter P 2008 Back muscle as a promising site for ovarian tissue transplantation, an animal model. Human Reproduction 23 619-626. (doi:10.1093/humrep/dem405)

Soleimani R, Heytens E, Van den Broecke R, Rottiers I, Dhont $M$, Cuvelier CA \& De Sutter P 2010 Xenotransplantation of cryopreserved human ovarian tissue into murine back muscle. Human Reproduction 25 1458-1470. (doi:10.1093/humrep/deq055)

Soleimani R, Heytens E \& Oktay K 2011 Enhancement of neoangiogenesis and follicle survival by sphingosine-1-phosphate in human ovarian tissue xenotransplants. PLOS ONE 6 e19475. (doi:10.1371/journal.pone. 0019475)

Soleimani Mehranjani M, Noorafshan A, Hamta A, Momeni HR, Abnosi MH, Mahmoodi M, Anvari M \& Hazaveh M 2010 Effects of vitamin $E$ on ovarian tissue of rats following treatment with p-nonylphenol: a stereological study. Iranian Journal of Reproductive Medicine 8 1-9.

Suzuki H, Ishijima T, Maruyama S, Yanagimoto Ueta Y, Abe Y \& Saitoh H 2008 Beneficial effect of desialylated erythropoietin administration on the frozen-thawed canine ovarian xenotransplantation. Journal of Assisted Reproduction and Genetics 25 571-575. (doi:10.1007/s10815-008-9271-9) Van Eyck AS, Bouzin C, Feron O, Romeu L, Van Langendonckt A, Donnez J \& Dolmans MM 2010 Both host and graft vessels contribute to 
revascularization of xenografted human ovarian tissue in a murine model. Fertility and Sterility 93 1676-1685. (doi:10.1016/j.fertnstert. 2009.04.048)

Wang Y, Chang Q, Sun J, Dang L, Ma W, Hei C, Shen X, Zhao C, Cai Y, Pei X et al. 2012 Effects of HMG on revascularization and follicular survival in heterotopic autotransplants of mouse ovarian tissue. Reproductive Biomedicine Online 24 646-653. (doi:10.1016/j.rbmo.2012.02.025)

Yang H, Lee HH, Lee HC, Ko DS \& Kim SS 2008 Assessment of vascular endothelial growth factor expression and apoptosis in the ovarian graft: can exogenous gonadotropin promote angiogenesis after ovarian transplantation? Fertility and Sterility 90 1550-1558. (doi:10.1016/ j.fertnstert.2007.08.086)
Yasuda Y, Fujita Y, Musha T, Tanaka H, Shiokawa S, Nakamatsu K, Mori S, Matsuo T \& Nakamura Y 2001 Expression of erythropoietin in human female reproductive organs. Italian Journal of Anatomy and Embryology $106215-222$.

Received 14 August 2013

First decision 14 October 2013

Revised manuscript received 28 January 2014

Accepted 3 February 2014 